ORIGINAL ARTICLE

\title{
Role of Combined Mifepristone and Misoprostol Verses Misoprostol Alone in Induction of Labour in Patients with Intrauterine Foetal Death - a Randomized Comparison Between their Outcome
}

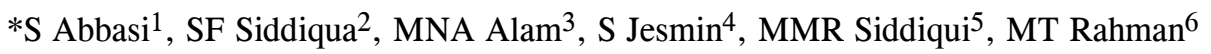 \\ ${ }^{1}$ Dr. Sharmin Abbasi. Assistant Professor, Gynecology and Obstetrics- Anwer Khan Modern Medical College Hospital \\ ${ }^{2}$ Prof. Sehereen Farhad Siddiqua. Professor and Head Gynecology and Obstetrics- Anwer Khan Modern Medical College Hospital \\ ${ }^{3}$ Dr. Mohammad Noor-A-Alam. Assoc. Professor and Unit Head, Surgery. BIRDEM \\ ${ }^{4}$ Dr. Suha Jesmin. Assoc.Professor Gynecology and obstetrics- Anwer Khan Modern Medical College Hospital \\ ${ }^{5}$ Dr. Md. Mahmudur Rahman Siddiqui, Assoc.Professor, Medicine Anwer Khan Modern Medical College Hospital \\ ${ }^{6}$ Prof. Md. Tahminur Rahman, Prof of Pathology and Vice Principal Anwer Khan Modern Medical College Hospital \\ *Corresponding Author \\ Date of submission: 09.04.2016 Date of acceptance: 17.11.2016
}

\begin{abstract}
Background: Intrauterine fetal death is means- intrapartum death after the fetus has reached the age of viability ${ }^{8}$. As in IUFD journey, labor pain will be fruitless. So, it is of utmost importance to search for the method which can reduce hours of pain in labor of IUFD cases.

Metarials Methods: In this research work patients divided in two groups. Induction of labour in one group was given by combination of mifepristone and misoprostol other group by misoprostol only and we try to find out the best method. To compare the effectiveness, induction to delivery interval, safety and side effects of combination of mifepristone and misoprostol versus conventional use of misoprostol alone in induction of labour in patients with intrauterine fetal death. It is a Prospective randomized comparative study in Anwer Khan Modern Medical College Hospital and Dhaka Medical College Hospital among 70 patients with IUFD after 28 weeks of gestation during January 2014- January 2016.
\end{abstract}

Result: We allowed the patients up to third gravid and after 28 weeks of gestation. Patients were grouped as Group A(35) \& Group B (35). In Group A Induction was given by single oral dose of $200 \mathrm{mg}$ mifepristone, and after 48 hours, tab. Misoprostol in post. fornix started if $<34$ weeks-100 $\mu \mathrm{gm}$ dose and $>34$ weeks-50 $\mu \mathrm{gm}$ dose. Doses were repeated every 6 hourly intervals if required. In Group B Induction was given by $100 \mu \mathrm{gm}$ misoprostol at 6 hourly interval in post. Fornix. In both groups we allowed misoprostol maximum $600 \mu \mathrm{gm}$. Oxytocin was given for augmentation if needed. The two study groups did not differ demographically. Induction to delivery time was shorter with combined regimen group $(\mathrm{P}<0.001)$. Induction to delivery interval ranges from $10-12$ hours in mifepristone plus misoprostole group.In only misoprostol group it was about 24-26 hours. Doses of misoprostol was lower in combined group $(\mathrm{P}<0.001) .4$ patients need Oxytocin for augmentation in only misoprostol group. In combined group oxytocin was not needed. The two groups did not differ as regards complications experienced during labour and delivery significantly. In overall out come 2 failed induction in misoprostol only group but not in combinedgroup.

Conclusion: In Induction of IUFD mifepriston plus misoprostol is an effective combined group. It is safe, non invasive, easily tolerable, highly cost effective, had less induction to delivery interval, required less dose of misoprostol and no need of augmentation with oxytocin. So,the combined group is more effective than conventional regimen of misoprostol alone.

Key Words: Pregnancy, Intrauterine fetal death (IUFD), Mifepriston, Misoprostol, Oxytocin

\section{Introduction}

In spite of modern medical advancement, there is some significant pregnancy loss during antepartum period. ${ }^{9}$ This is a tragic event for mother, her family and the physicians who are providing the obstetric care. In some cases the foetus dies during delivery as a result of asphyxia or difficult labour and others are

seen in which it dies in utero before labour starts. To inform the diagnosis to the patients must be handled sensitively. ${ }^{10}$

In majority of cases labour soon follows death of the foetus, but sometimes labour does not start for several weeks. In these cases there may be no urgent call for

AKMMC J 2017; 8(1) : 50-54 
Role of Combined Mifepristone and Misoprostol Verses Misoprostol Alone interference, unless the complication of DIC occur. ${ }^{11}$ However most mothers want, induction of labour and delivery as soon as possible. The unfavorable cervix remains a well-recognized impediment to success of induction of labour in intrauterine foetal death. ${ }^{12} \mathrm{~A}$ variety of methods have been used for cervical change in recent years. ${ }^{13}$ Prostaglandins in different forms in different routes have been widely investigated to be used for induction of labour particularly when the cervix is unripe and had proven to be safe and effective. ${ }^{14}$ Oral misoprostol administration for labour induction with IUFD was first described in Sao Paulo, Brazil in 1978. 15 Repeated dose may caused many side effects such as uterine hyperstimulation and systemic side effects like nausea, fever, shivering, diarrhea always remains issue of concerns. Mifepriston is a steroid compound,which compete with progesterone at the receptor level. ${ }^{16}$ Mifepriston, administration before misoprostol increase the sensitivity of the uterus to prostaglandins and ripens cervix, thereby allowing lower doses of misoprostol to induce labour. The purpose of this study is to compare the effectiveness, safety, tolerence and side effects between combined regimen of mifepriston and misoprostol with conventional use of misoprostol alone in induction of labour in patients with intrauterine foetal death.

\section{Materials and Methods}

This is a prospective randomized study in Anwer Khan Modern Medical College Hospital and Dhaka Medical College Hospital among 70 patients with IUFD after 28 weeks of gestation during January 2014 - January 2016. We allowed the patients after 28 weeks of gestation, single pregnancy, up to third gravid, intact amniotic membrane, normal coagulation profile, patients had no history of APH (Abruptio placenta or Placenta Previa), no history of bronchial asthma, glaucoma, hypersensitivity to prostaglandin, myomectomy or uterine perforation and had no history of previous cesarean section. Diagnosis was made by clinical and USG findings. After taking informed written consent patients were grouped as Group A (35) \& Group B (35). In Group A Induction was given by single oral dose of $200 \mathrm{mg}$ mifepristone, and after 48 hours, tab. Misoprostol in post.fornix started with $100 \mu \mathrm{gm}$ dose if the gestational age less than 34 weeks and if more than 34 weeks then $50 \mu \mathrm{gm}$ dose were given. Doses were repeated every 6 hourly intervals if required. In Group B Induction was given by $100 \mu \mathrm{gm}$ misoprostol at 6 hourly interval in post. Fornix. In both groups we allowed misoprostol maximum 600 $\mu \mathrm{gm}$. Oxytocin was given for augmentation if needed. During the periods pulse, BP, Temperature, uterine contraction, symptomatic symptoms were monitored hourly. Those who had fever managed by paracetamol and analgesics to reduce pain.

\section{Results}

Mean gestational age of the patient was 34.17. \pm 2.11 wks in combined group and $35.64 \pm 2.12 w k s$ in misoprostol group. Average age of patient was $26.92 \pm 2.19$ years for combined group and $25.06 \pm 1.1$ years for misoprostol group.

Table-I: Percentage distribution of the induction of labour among both study groups on the basis of Demographic characteristics of patients.

\begin{tabular}{lrll}
\hline Parameters & $\begin{array}{c}\text { Combined group } \\
\mathbf{n}=\mathbf{3 5}\end{array}$ & $\begin{array}{c}\text { Misoprostol } \\
\text { group } \\
\mathbf{n}=\mathbf{3 5}\end{array}$ & P value \\
\hline $\begin{array}{l}\text { Age(yrs) } \\
\text { Mean } \pm \text { SD }\end{array}$ & $26.92 \pm 2.19$ & $25.06 \pm 1.1$ & Ns \\
Gravidity & $22(64.5) \%$ & $16(50.4) \%$ & Ns \\
Primi & $12(34.3) \%$ & $18(51.6) \%$ & \\
Multi & $34.17 . \pm 2.11$ & $35.64 \pm 2.12$ & Ns \\
Gestational Age (weeks) & & & \\
& & & \\
ns = not significant & & & \\
s=significant & & & \\
\hline
\end{tabular}

Table: 1 Showed that the result from this small study groups did not differ demographically. Mean gestational age of the patient was 34.17. \pm 2.11 wks in combined group and $35.64 \pm 2.12 \mathrm{wks}$ in misoprostol only group.

Table-II: Number of doses of misoprostol in two groups

\begin{tabular}{|c|c|}
\hline Combined Group & Misoprostol \\
\hline $\operatorname{Mean} \pm$ SD & P - Value \\
\hline \multirow{3}{*}{$1.89 \pm .96$} & Mean \pm SD \\
\hline & $3.41 \pm .12$ \\
\hline & $<0.01(\mathrm{~s})$ \\
\hline
\end{tabular}

Table: 2 In this analysis it showed that dose of misoprostol is needed more in misoprostol only group than combined group and the findings are significant $\mathrm{P}(<0.01)$. 


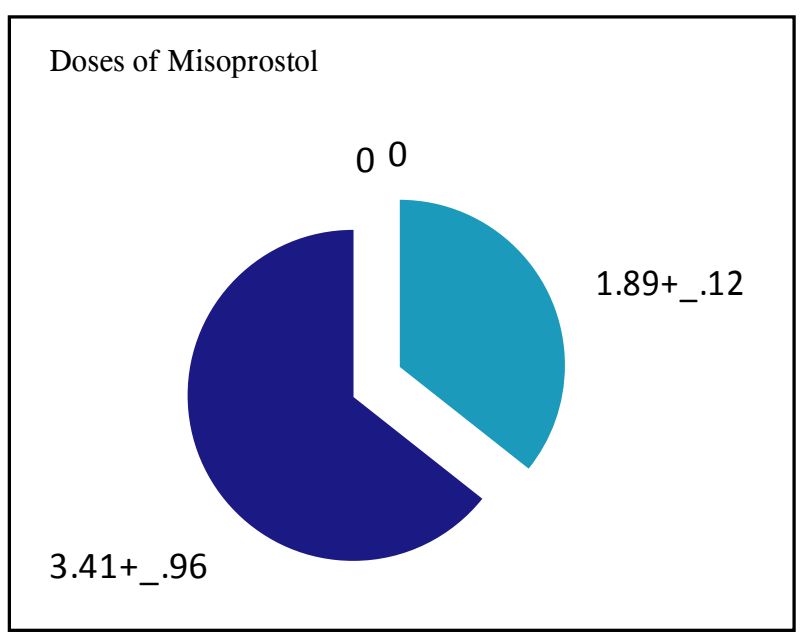

Figure 1: Doses of misoprostol in combined group and misoprostol alone group.

During the analysis it showed that requirement of oxytocin is minimum in both groups because for the few patients augmentation was need.

Table III: Percentage distribution of Requirement of oxytocin drip between two groups

\begin{tabular}{lccc}
\hline Drip & $\begin{array}{c}\text { Combined } \\
\text { gro up }\end{array}$ & $\begin{array}{c}\text { Misoprostol } \\
\text { group }\end{array}$ & P-value \\
\hline & $\mathrm{n}=35(\%)$ & $\mathrm{n}=35(\%)$ & \\
Given & $0\left(\begin{array}{ll}0 & \%\end{array}\right)$ & $4(14.2)$ & \\
Not Given & $35(100 \quad \%)$ & $31 \quad(84.5)$ & $>1.00$ \\
\hline
\end{tabular}

Table III Shows that small number no patients needed oxytocin drip in combined group and 4 (14.2) \% patients needed oxytocin drip in misoprostol only group, $100 \%$ patient in combined group \& $84.5 \%$ patient in misoprostol only group delivered without oxytocin drip.

Induction to delivery interval is very important for a patient because when it took more time it caused more mental and physical distress for the mother. In our study in combined group the interval was significantly lower $(13.97 \pm 3.75)$ hrs than $(24.24 \pm 3.19)$ hrs in misoprostol only group.
Table IV: Percentage distribution of Induction to delivery interval (hour) in two groups

\begin{tabular}{cccc}
\hline $\begin{array}{c}\text { Induction to } \\
\text { onset of labour } \\
\text { (hours) }\end{array}$ & $\begin{array}{c}\text { Misoprostol } \\
\text { only } \\
\mathbf{n}=\mathbf{3 5}(\%)\end{array}$ & $\begin{array}{c}\text { Combined } \\
\text { group } \\
\mathbf{n}=\mathbf{3 5}(\%)\end{array}$ & P-value \\
\hline $6-12$ & $4(11.76)$ & $9(27.27)$ & \\
$12-24$ & $9(25.29)$ & $17(51.27)$ & \\
$24-36$ & $16(47.06)$ & $7(21.21)$ & \\
$>36$ & $6(19.96)$ & $2(6)$ & \\
Mean \pm SD & $24.24 \pm 3.19$ & $13.97 \pm 3.75$ & $<0.01(\mathrm{~s})$ \\
$\mathrm{s}=$ Significant & & & \\
\hline
\end{tabular}

Table IV: Showed that mean induction to delivery interval time was significantly different in both group. For the combined group mean time $13.97+3.75$ hours to delivery in contrast with misoprostol onlt group which needed $24.24+3.19$ hours.

We hourly cheak the vital signs of the patients. Maternal complication were very few in two groups.Vomiting, diarrhea, fever, chills and rigor were recorded in some patients. Uterine hyperstimulation, uterine tachysystole, haemorrhage or DIC were not recorded in any groups.

Table V: Maternal complication after induction of labour

\begin{tabular}{lcc}
\hline Complication & $\begin{array}{c}\text { Combined } \\
\text { group } \\
\mathbf{n}=\mathbf{3 5}(\boldsymbol{\%})\end{array}$ & $\begin{array}{c}\text { Misoprostol } \\
\text { gr oup } \\
\mathbf{n}=\mathbf{3 5}(\boldsymbol{\%})\end{array}$ \\
\hline $\begin{array}{l}\text { Fever }>100^{\circ} \mathrm{F} \\
\begin{array}{l}\text { Gastro intestinal } \\
\text { symptom }\end{array}\end{array}$ & $2(5.9)$ & $3(9.1)$ \\
Postpartum hemorrhage & 0 & $3(9.1)$ \\
Hyperstimulation & 0 & $1(2.9)$ \\
Retained Placenta & $1(2.45)$ & $1(2.9)$ \\
No complication & $31(85.7)$ & $3((.1)$ \\
\end{tabular}

Table 5 Showed that maternal complications were few. The most common complication among vaginal deliveries was elevated temperature $\left(>100^{\circ} \mathrm{F}\right)$. Risk of fever, postpartum hemorrhage, and hyperstimulation did not differ significantly.

We also compared the overall out come of the patient and their total days of hospital stay. In misoprostol 
Role of Combined Mifepristone and Misoprostol Verses Misoprostol Alone group, one patient needed caesarean section due to failed induction.

Table VI: Outcome of induction measures and hospital stay

\begin{tabular}{cccc}
\hline Parameters & $\begin{array}{c}\text { Combined } \\
\text { group } \\
\mathbf{n}=\mathbf{3 5}(\%)\end{array}$ & $\begin{array}{c}\text { Misoprostol } \\
\text { group } \\
\mathbf{n}=\mathbf{3 5}(\%)\end{array}$ & P -value \\
\hline $\begin{array}{l}\text { Outcome } \\
\text { Successful } \\
\text { induction }\end{array}$ & $35(100)$ & $33(97.4)$ & \\
$\begin{array}{l}\text { Failed induction } \\
\text { Hospital stay (hrs) }\end{array}$ & $12-18$ & $24-36$ & $>0.10$ \\
\hline
\end{tabular}

Table VI Shows that most of the patients $100 \%$ in combined group and $97.4 \%$ in misoprostol group delivered vaginally after induction in both groups, $2.9 \%$ patients needed caesarean section in misoprostol group.Hospital stayed in both groups was almost similar.

\section{Discussion}

Induction of labour in IUFD is a standard obstetric approach in properly selected patients. Achievement of vaginal delivery for a woman who requires induction of labour in intra uterine foetal death should be simple, safe, effective and non invasive. ${ }^{17}$ Before mifepriston or prostaglandins become available. attempts to induce labour after foetal death sometimes turned into iatro-genic nightmares because of the unreliability and the risks of the available methods. The methods used included estrogen administration, intraamniotic injection of hypertonic solutions and high doses of oxytocin. 18 Discouraged by oestrogen administration and a number of maternal deaths attribute to hypertonic intrauterine instillation, most obstetricians have tended to rely on high doses of oxytocin, if they were at all inclined to pursue elective delivery. ${ }^{19}$ Effective doses of injection nearly always lead to some degree of water retention, and the infusions often had to be stopped and then repeated after a suitable delay. Instead of diminishing emotional upset, the procedure aggravated it, leaving the woman exhausted after very failed attempt to induce labour. ${ }^{20}$
Clinical interest is growing in PGE1 misoprostol, which is available as tablet containing $200 \mathrm{gm}$ of misoprostol. And mifepristone is available in tablet form containing $200 \mathrm{mg}$. This is prospective comparative study of 70 patients with intra-uterine foetal death were recruited 35 in each group, from in patient department of obstetrics and gynaecology of AKMMCH and DMCH.

Demographic, socioeconomic and obstetric characteristics were compared between two groups. The result from this small study shows that the two study groups did not differ demographically (Table 1). There were no statistically significant difference in maternal age, gravidity and antenatal check up (Table 1). Most of the patients came from poor socioeconomic condition had no antenatal check up. Analysis of the United States Birth Statistics (National centre for Health Statistics) shows that approximately $10 \%$ of all induction requires cervical ripening. The state of cervix is the most important decisive factor in determining the successful outcome. There can be little doubt that local prostaglandin plays an important role in softening and ripening the cervix to render it more favourable for induction. The induction by prostaglandin in clinical use has not only increased the efficacy in case of unripe cervix but has also proved to be a very effective oxytocic bridging between the two interlinked component of labour (cervical ripening). ${ }^{21}$

In this prospective study (Table 2), dose of misoprostol is needed more in misoprostol only group $(3.41 \pm .12)$ than combined group $(1.89 \pm .96)$ and the findings are significant $\mathrm{P}(<0.01)$.

One study showed that a single dose of mifepriston plus misoprostol than vaginal misoprostol was more effective. ${ }^{22}$

In my study small number $1(2.85 \%)$ patient needed oxytocin drip in combined group and 5 (14.2) \% patients needed oxytocin drip in misoprostol only group, $97.14 \%$ patient in combined group \& 84.5\% patient in misoprostol only group delivered without oxytocin drip.

In my series mean induction to delivery interval time was significantly different in both group. For the combined group mean time $13.97+3.75$ hours to delivery in contrast with misoprostol onlt group which needed $24.24+3.19$ hours. In Indian study reported similar observation. 
One study showed about 65 patients combined regimen and 62 patients received misoprostol only tablet. Combined group was associated with more rapid cervical repining. Shorter induction to vaginal delivery interval and greater number of vaginal deliveries with in 24 hours. ${ }^{23}$

Most of the patients successfully delivered vaginally without any complications in both groups in this study. The most common complication among vaginal deliveries was elevated temperature $\left(>100^{\circ} \mathrm{F}\right)$. Risk of fever, postpartum hemorrhage, and hyperstimulation did not differ significantly. Previous one study showed that incidence of tachy systole found in misoprostol only group. There was a case report that uterine rupture in a primigravida with misoprostol used for induction of labour. ${ }^{24}$

There was no significant difference in successful delivery outcome. Most of the patients $100 \%$ in combined group and $97.4 \%$ in misoprostol group delivered vaginally after induction. $2.9 \%$ patients needed caesarean section in misoprostol group due to failed induction. Hospital stayed in both groups was almost similar. More cases required analgesia in misoprostol group as compared to combination group which can be directly correlated with length to contraction or duration of labour. Although we preferred to keep all patient admitted in hospital after administration of mifepriston for observation , no adverse event was found.

Safe technique should be used that minimized side effects, involves a natural uterine contraction response and decrease cost is optional. ${ }^{25}$

\section{Conclusion}

In induction of Intrauterine fetal death (IUFD) mifepristone plus misoprostol is an effective combined group. It is safe, non invasive, cost effective, easily tolerable and more effective with less induction to delivery interval than conventional regimen of misoprostol alone.

Conflict of Interest: Authors declared that they have no conflict of interest.

\section{References}

7. Rantam S S, Rao K B , Kumaran SA.Induction of labour after intrauterine foetal death obstetrics and gynaecology.Orient Longman limited, 2004; 206, 252.

8. Charmers I Murry Enkin and Marc J.N.C. Kreise,Induction of labour after death.Effective care in pregnancy and child birth, 2009; 2: 1118-1124.
9. Calder AA Embrey MP and Tait T. Ripening of cervix with extra amniotic prostaglandin E2 in viscous gel before induction of labour.Br. J Obstet Gynaecol 2011; 84: $264-8$

10. John Patrick O Grady, MD; David E. Seubert, MD: Christian S. Pope, Do; Despina E. Hoffman. BA. Use of misoprostol in Obstetric Practice.N Engl J Med 2012; 340: 333

11. Datta DC, Pharmacotherapeutics, Textbook of in Obstetrics, 6th ed, New central book agency 2005; 505

12. Chamberlin C.V.P Vital statistics obstetrics by Ten teachers, 16th Edition 2011, 357-358

13. Mutannabi $M$, Information of perinatal health, $5^{\text {th }}$ national conference and scientific seminar; 2005, 37

14. Bashkar Rao, Perinatal mortality. S Aruul Kumaran and A. Biswas. Induction of labour after foetal death, orient longman limited 2007; 206, 252

15. Huang, D-Y, UsherR-H, Karmer, M-S, Yang-h; Morin, L. Determinants of unexplain antepartum foetal death; Obstet Gynaecol, 2013

16. Vital statistics obstetrics by Ten teachers, 16th Edition 2006, 357-358

17. Mutannabi $M$, Information of perinatal health, $5^{\text {th }}$ national conference and scientific seminar; 2005, 37

18. Demographic Surveillance system-Matlab, Registratuon of Demographic Events,1993. Scientific Report, May 2013, 24

19. Bashkar Rao, Perinatal mortality. S Aruul Kumaran and A. Biswas. Induction of labour after foetal death, orient longman limited 2004; 206, 252

20. Huang, D-Y, Usher R-H, Karmer, M-S, Yang-h; Morin, L. Determinants of unexplain antepartum foetal death; Obstet Gynaecol, 2000

21. Skjoldebrand-spare,:Toljvenstam, T Papadog-iarnakis, N wharan-B, Broliden, Nyman, Parvo virus B19 infection association with third trimesterintrauterine foetal death; BJOG, 2000, 107(4); 476-80

22. Harry J, Loughrin, MD, Thomas H.Kirschbaum, MD. Intrauterine foetal death-Principle and Practice of Obstetrics and perinatology, 1st ed 1999; 65: 11351153.

23. Clayton, Lewis, Pinker, The Fetus at risk in late pregnancy; Intra utrrine Foetal death Obstetrics, $14^{\text {th }}$ ed, 2002; 213-214

24. Prasai S: Outcome of induction of labour in primigravida term patient with poor bishop score with or without priming with PGE2 gel. Bangladesh College of Physicians and Surgeons, 2000; 2: 76-9

25. Easmin S, Nahar K, Jahan MK, Rahim R, Nila TA, Nigar K, Khan NA: Intravaginal use of misoprostol for induction of labour in intrauterine death, Mymensingh Med J. 2011 oct, 20(4), 566-9 